\title{
Teaching System of Smart Learning Environment for Aerobics Course
}

\author{
https://doi.org/10.3991/ijet.v13i05.8440 \\ Yanan $\mathrm{Yu}^{(凶)}$ \\ Shandong Normal University, Jinan, China \\ yynlt@ $126 . \mathrm{com}$ \\ Aili Qi \\ Guizhou University of Engineering Science, Bijie, China
}

\begin{abstract}
In the past, in a digital learning environment, we required multimedia facilities excessively and ignored the individual needs of learners, and the teaching resources existed depending on the equipment. The emergence of smart learning environment can meet people's independent learning, customized learning, smart learning and other requirements. Meanwhile, the "intelligence" of smart learning environment conforms to the teaching features of aerobics and other body-shaping courses, which can cultivate the learners' innovation abilities and further optimize the teaching effect. In this paper, on the basis of the theory construction of smart learning environment, we designed a teaching system of smart learning environment for the university course - Aerobics, based on the Fuzzy Cognitive Map (FCM), conducted the application practice of the smart learning environment in the teaching by the controlled experiment method, analyzed the difference of teaching effect in and out of a smart learning environment, and finally drew a conclusion, in order to provide some theoretical and data support for the application of smart learning environment in the teaching of physical education (PE) majors and other university education.
\end{abstract}

Keywords-Fuzzy Cognitive Map (FCM), smart learning environment, teaching system, aerobics

\section{Introduction}

The smart learning environment is generated based on the information and communication technology, which is learner-centered and takes the effective learning as the purpose in the background of modern educational technology [1]. In this environment, the system can perceive the scenes of learning activities, and identify students' characteristics and select appropriate teaching resources for them automatically. Meanwhile, the teaching system of smart learning environment is able to record the learning process accurately and finish the learning evaluation in time. The teaching in the smart learning environment is carried out with the smart mobile devices as the electronic learning material. This learning material not only has all functions of paper 
textbooks, but also has multimedia and is individualized, which can link related knowledge points, analyze learners' learning results intelligently and show the results graphically, so as to provide some guidance for learners.

The smart learning environment is obviously different from the digital learning environment in the learning resource, learning tool, teaching and learning methods, social community, etc. In the past, in a digital learning environment, we required the multimedia facilities excessively and ignored the individual needs of learners, and the teaching resources existed depending on the equipment. However, in a smart learning environment, we can provide the resources as required. In terms of learning tools, in a smart learning environment, learners can perceive the technological environment automatically without judgment, and the tools show a trend of specialization and miniaturization. On the teaching and learning methods, we place particular emphasis on the explanation in the digital learning environment but focus on the guidance in the smart learning environment, so it has some obvious advantages. In terms of the social community, a community can be formed automatically in the learning environment, where teachers and learners can communicate with each other at anytime and anywhere [2].

At present, the practice of smart learning environment has been carried out in many fields, such as natural science [3] and language and art [4]. Taking a course about butterfly and ecology in a middle school as an example, the smart learning environment provided students with real visual and tactile feelings, and students could get close to the living environment of butterflies in the learning process gradually, so as to improve their learning effect effectively in the cooperation and communication [5]. In this paper, we designed the teaching system of smart learning environment based on FCM for the university course - Aerobics. It is expected to be introduced the into the university PE and provide new ideas for the teaching of PE majors with Aerobics as a representative.

\section{State of the art}

In the background of modern education, it is more urgent for the teaching of PE majors such as Aerobics or other body-shaping courses to demand the advanced technology and optimized learning environment, so people hope to design a more intelligent and personalized teaching system for the practical teaching [6]. In recent years, the smart learning environment has gradually become a research hotspot of scholars at home and abroad, such as the experts and scholars from the field of computer science and education, most of whom focused on the development trend and evaluation model of smart learning environment. For example, researchers put forward the concept of smart learning environment from the perspective of the demand of social informatization for the reform of learning environment and pointed out that the smart learning environment was a high-end form of digital learning environment, and its purpose was to urge learners to study effortlessly, attentively and effectively. In this research, researchers analyzed the differences between the digital learning environment and the smart learning environment in detail and summarized the characteristics that the smart 
learning environment should have [7]. Some other researchers deduced the corresponding evaluation model of smart learning environment according to its "intelligence", namely, evaluating the intelligence of the objects such as hardware system and software system and the living beings such as teachers, students and communities at the same time. Besides, in the actual evaluation, we shall make flexible adjustments according to the difficulty and particularity of courses, so as to obtain more accurate evaluation results [8].

Some scholars focus on the research of the architectural design of smart learning environment and the corresponding learners' emotion prediction models [9]. The scholars Watson et al. [10] completed the design of the overall structure of smart learning environment based on the intelligent information technology and the development connotation of learners, including the smart class, smart classroom, smart learning center and other different modules, which can realize the resource sharing, the dynamic expansion of system and other functions. In short, China has paid attention to the theoretical analysis and empirical research of smart learning environments. However, at present, there has been no report on the research of the learning characteristics of sports, art and other related majors, and no research on the integration of emotion prediction modules into the remote network teaching system of art, sports and other majors. In this paper, on the basis of the theory construction of smart learning environment, we designed a teaching system of smart learning environment based on FCM for the course Aerobics, in order to drive the development of PE teaching and provide theoretical support for the further promotion of smart learning environment.

The teaching system of smart learning environment based on FCM for the course Aerobics mentioned in this paper has two advantages as follows: on the one hand, the teaching system meets the needs of learning Aerobics and other body-shaping courses and fully considers the movement standard of aerobics and the requirements for the learners' creation abilities, so that the system can be carried out for the art and PE for the first time; on the one hand, the smart learning environment mentioned in this paper can predict learners' current emotional state instantly and provide important reference for the dynamic adjustment of teaching strategy, so that the system can adjust the teaching content timely and effectively to stimulate the learners' enthusiasm and improve their learning efficiency.

\section{Theoretical construction}

\subsection{FCM Fuzzy Cognitive Map (FCM)}

The FCM [11] is a graph model [5] composed of nodes and weighted directed arcs to show the causalities between concepts. The nodes are used to express the concepts, causes, results, tendencies, trends and other factors of the system. The directed arcs are used to express the causalities between concepts. The basic structure is as Fig.1: 


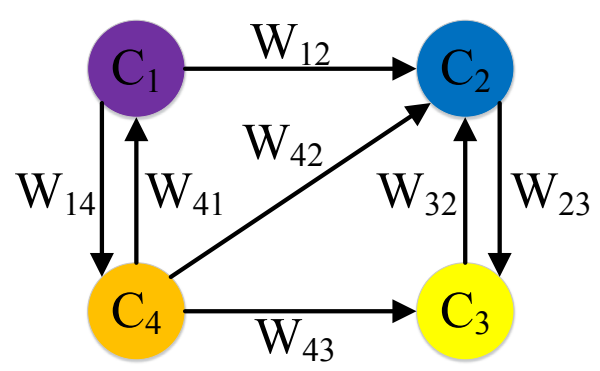

Fig. 1. The basic structure of FCM

In the structure, $\mathrm{C} 1$ to $\mathrm{C} 4$ are the conceptual nodes, whose attributes are represented by the status value of node. The degree of causality is represented by the weight $w_{i j}$, and $w \in[-1,1]$. The link matrix of the causalities between all nodes in the figure is as Fig.2:

$$
w_{i j}=\left[\begin{array}{cccc}
0 & w_{12} & 0 & w_{14} \\
0 & 0 & w_{23} & 0 \\
0 & w_{32} & 0 & 0 \\
w_{41} & w_{42} & w_{43} & 0
\end{array}\right]
$$

Fig. 2. The link matrix of the causalities between all nodes

When $w_{i j}>0$, then causality between the node $C i$ and $C_{j}$ is positive; when $w_{i j}<0$, it is negative; when $w_{i j}=0$, there is no obvious causality between them.

Based on the original state of the system nodes preset, FCM can complete the running process of simulation of the dynamic system and output the result according to the original state input. The computation rules of reasoning process are as follows:

$$
\begin{gathered}
A^{k+1}=f\left(A^{k}+\sum_{\substack{j \neq i \\
j=1}}^{n} A_{j}^{k} \times \mathrm{w}_{\mathrm{ji}}\right) \\
\mathrm{f}(\mathrm{x})=\frac{e^{2 x}-1}{e^{2 x}+1}
\end{gathered}
$$

In the formulas, $A_{1}^{k+1}$ and $A_{1}^{k+1}$ represent the values when the node $C_{i}$ is at $k$ and $k+1$ respectively; $w_{j i}$ is the weight between nodes; $f$ is the function of $S$ threshold value, which can translate the value of $C_{i}, A^{\mathrm{k}+1}$ into $[-1,1]$. 


\subsection{Learners' emotion prediction model based on FCM}

There are three steps to build the learners' emotion prediction model based on FCM: firstly, identify the main concepts, including the emotion influence factors and emotion attributes; secondly, evaluate the causalities between concepts to build an initial matrix; thirdly, update the link matrix by AHL. The learners' emotion prediction model based on FCM mentioned in this paper covers three layers of network, which are the input layer, hidden layer and output layer. The model structure is as Fig.3:

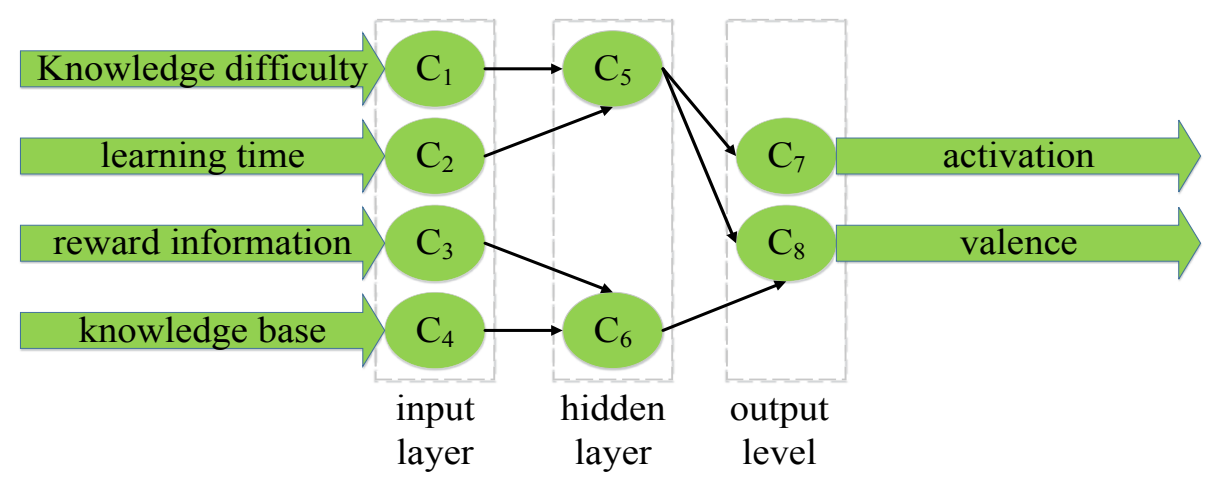

Fig. 3. The structure figure of learners' emotion prediction model

First of all, we selected the knowledge difficulty, learning time and so on as the input signals of the model. In the practical learning, these data come from the sensor attached to the smart learning environment. The nodes $C_{I^{-}} C_{4}$ in the output layer represent the knowledge difficulty, learning time, award information and knowledge base respectively.

Secondly, the hidden layer is responsible for receiving the data from the input layer. According to different emotion attributes, the hidden layer contains two nodes: $C_{5}$ is the degree of concentration, and $C_{6}$ is the value of learning interest. The node parameters are set based on the theories of neuropsychology and others. The degree of concentration is negatively affected by knowledge difficulty and learning time, but the value of learning interest is positively related to the award information and knowledge base. The two nodes in the hidden layer also affect each other. Namely, the increase of the value of learning interest will provide degree of concentration [6].

Thirdly, the output layer of the learners' emotion prediction model can reflect learners' emotion attributes directly, in which $C_{7}$ and $C_{8}$ represent the degree of activation and the valence respectively. By the processing in the three layers, the learners' emotion prediction model based on FCM can play a role in helping learners as the basis of smart learning environment. 


\subsection{The model building of smart learning environment}

The design of the smart learning environment is as follows: first, build a learning environment entity based on the hardware and software platform of Wisdom Cloud, which provides the smart classroom, smart laboratory, smart learning center, smart creation space and other optional models; secondly, connect all platforms with the cloud center, so as to realize the sharing of learning data and teaching resources. The overall structure of smart learning environment is as Fig 4:

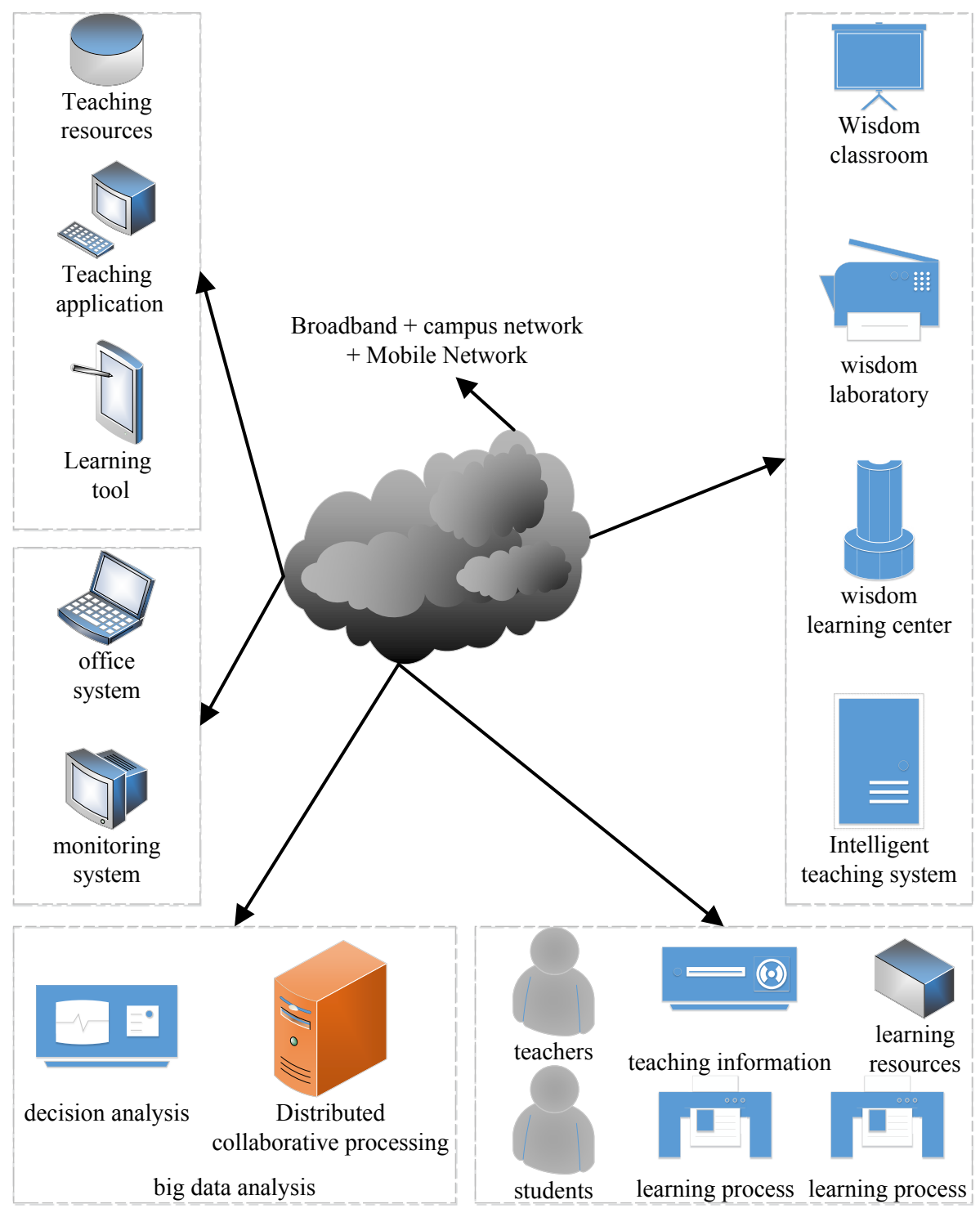

Fig. 4. The overall structure of smart learning environment 
We see from Fig 4 that the smart learning environment mainly covers the basic network, cloud platform, foundation database, and large data analysis module. The basic network is the foundation for the smart learning environment to run orderly; the cloud platform provides all kinds of software and hardware and supporting services required for the system operation; the foundation database contains the data of teaching information and teaching management of the system. The big data analysis module is the core of smart learning environment, which can make decision analysis, distribute the co-processing, and classify the system data effectively, so as to provide the intelligent support for the smart learning environment. The learners' emotion prediction model based on FCM just completes the analysis of learners' emotions in the big data analysis module, and then finishes the adjustment of teaching strategies, the matching of teaching resources and other measures.

\section{Construction of the teaching system of smart learning environment based on FCM for Aerobics}

The body-shaping courses with aerobics as a representative are carried out by the combination of gymnastics and dance with music and to extend the PE knowledge and skills at the same time. These courses require the participants to not only have high proficiency and accuracy in the designated movements, but also recreate and design the movements based on the basic movements, so as to improve the performance effect, highlight the theme of performance, and improve the creation abilities in aerobics. Therefore, the building of the teaching system of smart learning environment based on FCM for the university course Aerobics is carried out mainly centering on the smart classroom and the smart creation space, in order to solve the problem that the learners have insufficient creating abilities.

\subsection{The smart classroom for the university course Aerobics}

The smart classroom is mainly used for the classroom teaching of the university course Aerobics, including the theoretical knowledge and practical movements, in which the theoretical knowledge contains the basic terminologies of aerobics, competition rules, music and choreography, etc.; the practical movements are divided into four levels in accordance with the standards of mass aerobics dancing. The smart classroom will provide the learners with a place to learn theoretical knowledge and movements.

The design of smart classroom is divided into two parts: space design and technical design. The space shall be designed concisely, and the teaching facilities shall be distributed reasonably and realize the functions of dynamic combinations as far as possible, in order to provide the learners with a changeful learning environment. The technical design focuses on the intelligent control and centralized management, and the different modules and devices are connected with each other to achieve high interactivity by the wireless network. 
The basic devices of the smart classroom are the camera, smart blackboard, floor and so on. The application of the smart classroom to the teaching of the university course Aerobics will realize the functions such as the content presentation, environmental management, resource sharing, and situation obtainment. The designing draw of smart classroom is shown in Fig 5. Fig 6 is a screenshot of the courseware of smart teaching.

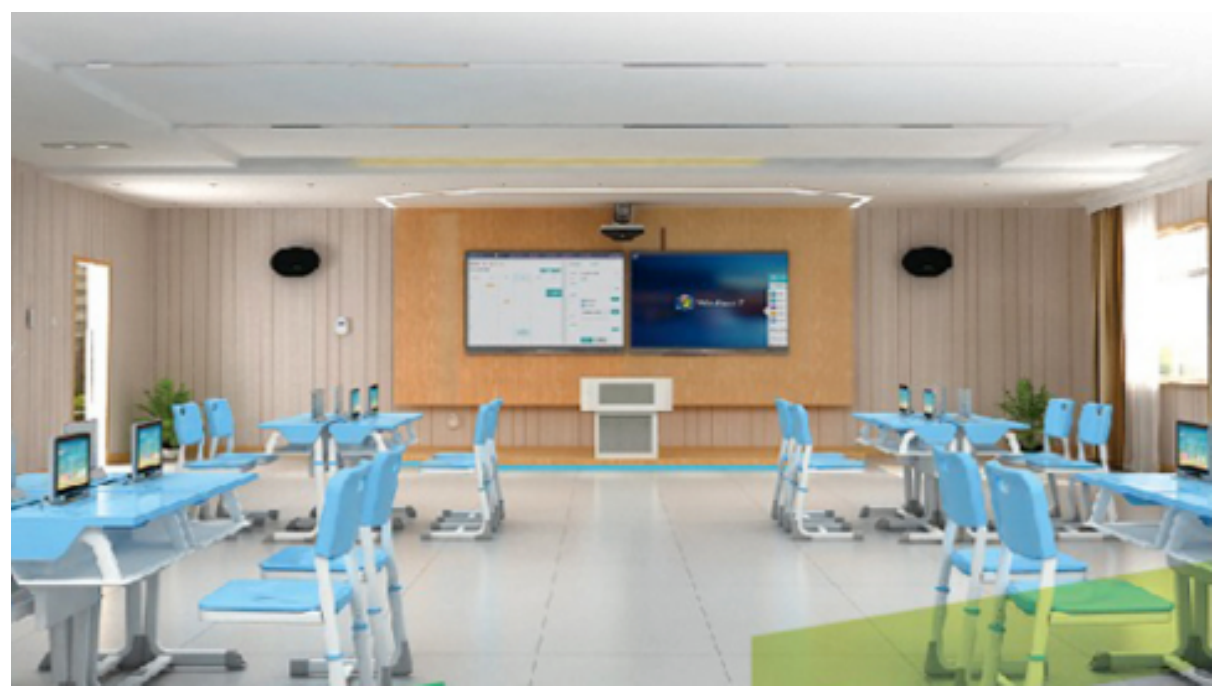

Fig. 5. Diagram of teacher management module

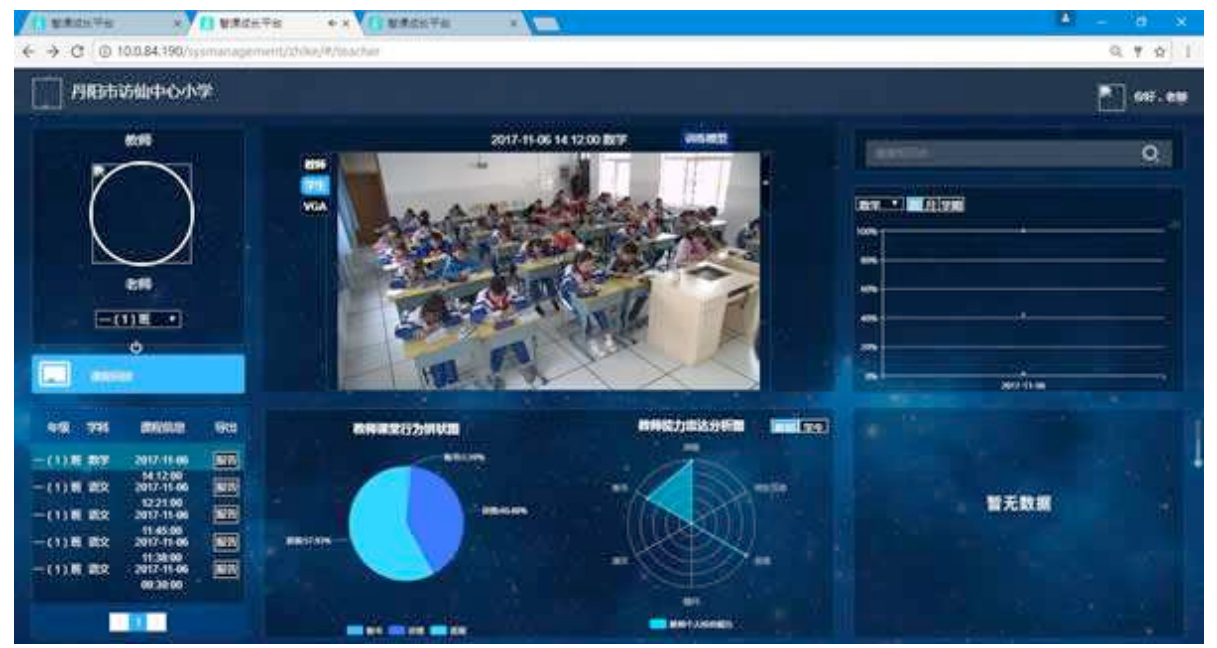

Fig. 6. A screenshot of the courseware of smart teaching 


\subsection{The Design of Smart Learning Environment based on FCM for Aerobics}

The design objective of smart learning environment is to cultivate the learners' abilities to create the aerobics, which is of great significance to the teaching of Aerobics. The design of smart learning environment is based on the learning theory to achieve the integration of resources, activity modes and learning environment. The basic devices of smart learning environment are the intelligence system, Open Source and block hardware, digital auxiliary tools, and social collaboration software, etc. The building of the smart creation space for the university course Aerobics is as follows:

Table 1. The building of smart learning environment for the university course Aerobics

\begin{tabular}{|l|l|}
\hline \multicolumn{1}{|c|}{ Type } & \multicolumn{1}{c|}{ Design } \\
\hline Environment integration & Online and offline interconnection and interworking \\
\hline Activity mode & Carry out diversified creation activities \\
\hline Activity form & Exchange information in normal courses, workshops and competition \\
\hline Activity pattern & Teachers' teaching, individual coaching and group cooperation \\
\hline Resource integration & Provide targeted and rich tools for creation \\
\hline
\end{tabular}

The smart learning environment designed in this paper can perceive the learners' sound, movements, emotional states, situations where they are located and other signals, and input them to the intelligent device. After the intelligent device analyzes and processes the signals perceived, the signals will complete the interaction automatically to achieve the improvement of teaching strategies and the targeted teaching guidance. The smart learning environment can provide support for the learners' creation in aerobics. On the one hand, the smart creation space can realize the connectivity of the existing creativity and design; on the other hand, the smart learning environment can realize the learners' communication and collaborative design. The link of the interaction between teachers and students in the smart learning environment is as shown in Fig 7.

\subsection{Effect check}

In this paper, we tested the application effect of the teaching system of smart learning environment in the course Aerobics by the controlled experiment method. We selected the sophomores of a sports college as the research objects, chose a class containing 50 students randomly as the experimental class, and took the teaching system of smart learning environment for it to assist teaching; and then we chose another class containing 50 students randomly as the control class and took the traditional teaching mode for it. There was no significant difference between the experimental class and the control class in teachers and teaching conditions, and no significant difference between the students of the two classes in age, sex, physical quality, understanding ability and so on.

The teaching progress was matched with the teaching arrangement, and the students were taught by a same teacher with a same teaching mode. In the theory teaching, the teacher took the teaching system of smart learning environment for the exper- 


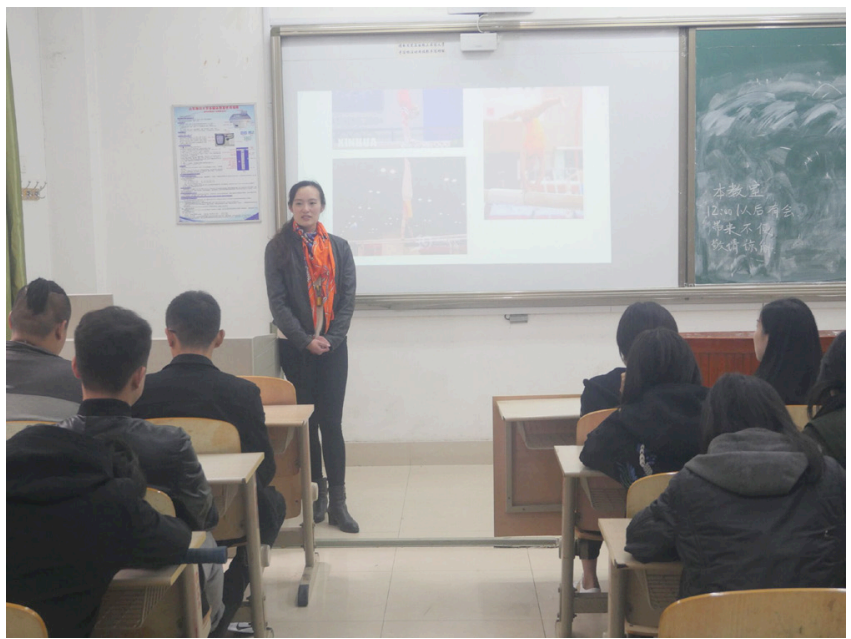

Fig. 7. The link of the interaction between teachers and students in the smart learning environment

imental class, while the control class still used the past learning model. The students' learning effect was evaluated mainly according to their creation abilities in aerobics. The students were evaluated in the form of separation of teaching and examination. The teachers for the evaluation of final-examination except the course teacher didn't know students' performance in class, who were more objective and fairer. In the evaluation of creative choreography, each 3 to 5 students should be grouped freely and create ten 8-meter aerobics movements, and each 8 -meters should be repeated in different directions, in which at least 6 to 8 movements should be different. The teachers should evaluate the students according to the fitness nature, scientific-ness, artistry and originality of the movements created by them.

After the course was over, the students of the experimental group and the control group were evaluated. The results are as shown in Fig 8:

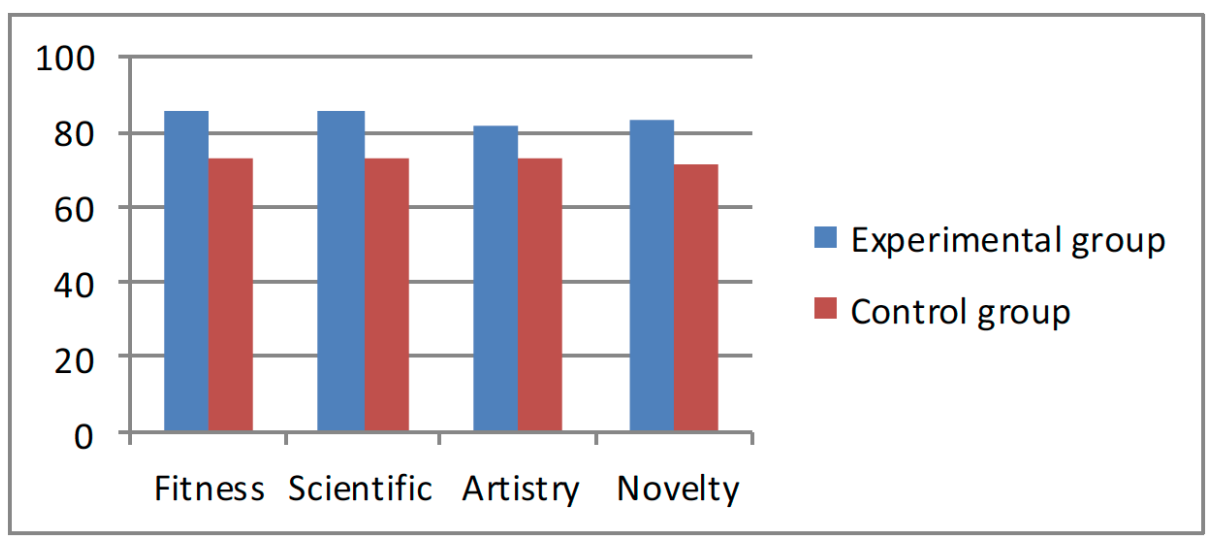

Fig. 8. The evaluation results of the creation in aerobics 
We can know from Fig 8 that, in the evaluation of the four aspects of creation ability in aerobics, the performance of the students in the experimental group is better than that of the control group greatly, and there is an obvious difference between the students' learning achievements in different learning environments. Therefore, the application effect of the teaching system of smart learning environment in the practical teaching of Aerobics is good, and it can improve students' creation abilities in aerobics effectively. Besides, the teaching system of smart learning environment based on FCM for the course Aerobics provides the learners with a picturesque teaching situation, where students can be inspired and guided by teachers to learn and create the movements of aerobics initiatively.

On the one hand, the smart learning environment completes the explanation of movements in virtue of the computer system, so that students can complete the whole creation after grasping the theory, methods and skills to create the aerobics. For example, the teaching content in the smart learning environment is richer and more flexible; teachers have more teaching materials and means in the more flexible forms, and they can take different teaching methods according to different teaching contents; the key points and difficulties in the teaching process are more prominent, and the details are more accurate; in the teaching of aerobics and other body-shaping courses, teachers don't have to demonstrate the movements repeatedly, which can be amplified and replayed continuously by the multimedia system.

On the other hand, the learners' emotion prediction model based on FCM in the smart learning environment is able to predict the learners' emotional states accurately. In the smart learning environment, it is a key for the intelligent network teaching system to build an effective learners' emotion prediction model for the predication of learners' emotions and timely responses. In this research, the emotion prediction module is integrated into the intelligent network teaching system to provide important reference for the dynamic adjustment of teachers' teaching strategies, help the remote systems adjust the teaching content timely and effectively, and mobilize students' enthusiasm fully and properly to complete the whole creation process initiatively.

\section{Conclusions}

The proposed and discussed teaching system of smart learning environment based on FCM for the teaching of aerobics has the rich function value. There are 2 key points in this method: the first is the building of FCM model; the second is the learners' emotion prediction method; the third is the practical combination of abovementioned method and PE teaching. The result show that the FCM model can predict the emotions accurately, which verifies the validity of the model and the rationality of the emotional space setting; the teaching system of smart learning environment meets the requirements for teaching Aerobics, and the teaching effect is good to improve the learning environment greatly. Therefore, the teaching system of smart learning environment based on FCM for the teaching of aerobics and other body-shaping courses has a very wide application prospect and high promotional value. 


\section{$6 \quad$ References}

[1] Widodo, J. Urban Environment and Human Behaviour: Learning from History and Local Wisdom. Procedia - Social and Behavioral Sciences, 2012, vol. 42(42), pp. 6-11. https://doi.org/10.1016/j.sbspro.2012.04.161

[2] Thomas, H. Learning spaces, learning environments and the displacement of learning. British Journal of Educational Technology, 2010, vol. 41(3), pp. 502-511. https://doi.org/10.1111/j.1467-8535.2009.00974.x

[3] Maor, D., Mcconney, A. Wisdom of the elders: mentors' perspectives on mentoring learning environments for beginning science and mathematics teachers. Learning Environments Research, 2015, vol. 18(3), pp. 335-347. https://doi.org/10.1007/s10984-015-9187-0

[4] Ya'acob, A., Nor, N.F.M., \& Azman, H. Implementation of the Malaysian smart school: An investigation of teaching-learning practices and teacher-student readiness. Internet Journal of e-Language Learning \& Teaching, 2005, 2(2), 16-25.

[5] Rusticus, S., Worthington, A., Wilson D, et al. The Medical School Learning Environment Survey: an examination of its factor structure and relationship to student performance and satisfaction. Learning Environments Research, 2014, vol. 17(3), pp. 423-435. https://doi.org/10.1007/s10984-014-9167-9

[6] Zhao, H.F., Lin, Z.R. Multiple Teaching of University Aerobics Course Guided by Multiple Intelligence Theory. Journal of Sports Adult Education, 2013, vol. 29(2), pp. 65-67.

[7] Jin, C., Debo, L., Iravani, S., \& Kremer, M. Observational Learning in Environments with Multiple Choice Options: The Wisdom of Majorities and Minorities. Social Science Electronic Publishing, 2015, vol. 8(4), pp. 262-270.

[8] Schlechter, A.F., Strauss, J.J. Leader emotional intelligence, transformational leadership, trust and team commitment: Testing a model within a team context. SA Journal of Industrial psychology, 2008, vol. 34(1), pp. 42-53. https://doi.org/10.4102/sajip.v34i1.418

[9] Shen, L., Wang, M., \& Shen, R. Affective e-learning: Using" emotional" data to improve learning in pervasive learning environment. Journal of Educational Technology \& Society, 2009, vol. 12(2), pp. 176-189.

[10] Watson, D.P., Young, J., Ahonen, E., et al. Development and testing of an implementation strategy for a complex housing intervention: protocol for a mixed methods study. Implementation Science, 2014, vol. 9(1), pp. 1-10. https://doi.org/10.1186/s13012-014-0138-4

[11] Amer, M., Jetter, A., \& Daim, T. Development of fuzzy cognitive map (fcm)-based scenarios for wind energy. International Journal of Energy Sector Management, 2011, vol. 5(4), pp. 564-584. https://doi.org/10.1108/17506221111186378

\section{$7 \quad$ Authors}

Yanan Yu is a lecturer in Shandong Normal University, Jinan 250014, China (yynlt@126.com).

Aili Qi is an associate professor in Guizhou University of Engineering Science, Bijie 551700, China. (qiailili@yeah.net).

Article submitted 13 February 2018. Resubmitted 18 March 2018. Final acceptance 28 March 2018. Final version published as submitted by the authors. 